\title{
Occurrence of natural dixenic associations between the symbiont Photorhabdus luminescens and bacteria related to Ochrobactrum spp. in tropical entomopathogenic Heterorhabditis spp. (Nematoda, Rhabditida)
}

\author{
Isabelle Babic, ${ }^{1}$ Marion Fischer-Le Saux, ${ }^{1}$ Eric Giraud ${ }^{2}$ and Noël Boemare ${ }^{1}$
}

Author for correspondence: Noël Boemare. Tel: +334 67143740. Fax: +33 467144679.

e-mail: boemare@ensam.inra.fr

1 Laboratoire de Pathologie Comparée, INRA-CNRS, IFR 56 'Biologie cellulaire et Processus infectieux', Université Montpellier II, CP 101, Place Eugène Bataillon, 34095

Montpellier Cedex 5, France

2 Laboratoire des Symbioses Tropicales et Méditerranéennes, CIRAD-IRD-INRA-AgroMontpellier, BP 5035, F-34032 Montpellier Cedex 1, France

\begin{abstract}
Bacteria naturally associated with the symbiont Photorhabdus luminescens subsp. akhurstii were isolated from the entomopathogenic nematode Heterorhabditis indica. Bacterial isolates distinct from $P$. luminescens subsp. akhurstii were obtained from $33 \%$ of the samples. Fourteen bacterial isolates, from nematodes collected from three different Caribbean islands, were characterized by conventional phenotypic tests, restriction fragment length polymorphism and sequence analyses of PCR-amplified 16S rRNA genes (16S rDNAs). Isolates were grouped into three genotypes, each one being associated with one Caribbean island. Phenotypic characteristics and 16S rDNA analysis showed that the Photorhabdus-associated bacteria were closely related to Ochrobactrum anthropi for the group from Guadeloupe, and to Ochrobactrum intermedium for the two groups from the Dominican Republic and Puerto Rico. No pathogenicity of the Ochrobactrum spp. to the insects Galleria mellonella and Spodoptera littoralis (Lepidoptera) was detected. Since Ochrobactrum spp. are considered as human opportunist pathogens, the mass production of entomopathogenic nematodes for biological control requires strict vigilance.
\end{abstract}

Keywords: Ochrobactrum spp., Photorhabdus luminescens, Heterorhabditis spp., 16S rRNA gene polymorphism and sequencing

\section{INTRODUCTION}

Steinernematidae and Heterorhabditidae are two families of entomopathogenic nematodes which are strongly virulent against a wide range of insects. Gaugler \& Kaya (1990) showed that they were non-pathogenic to mammals and suggested that they could be raised for use in biological control of insect pests. All Steinernema spp. carry in their gut symbiotic bacteria of the genus Xenorhabdus (Akhurst \& Boemare, 1988; Thomas \& Poinar, 1979), and all Heterorhabditis spp. carry symbiotic bacteria of the genus Photorhabdus (Akhurst et al., 1996; Boemare et al., 1993; Fischer-Le Saux et al.,

The EMBL accession numbers for the $16 \mathrm{~S}$ rDNA sequences reported in this paper are AJ245941 (PR17/sat), AJ249458 (FRG11/sat) and AJ249459 (DO23/sat).
1999). The symbiotic association plays an important role in both reproduction and pathogenicity of the nematodes (Boemare et al., 1996, 1997). After their penetration into the body cavity of the insect, the nematodes release their symbiotic bacteria into the insect haemolymph, inducing death by toxaemia and septicaemia.

It has been postulated that the monoxenic association between the nematode and its symbiont is due to antimicrobial compounds produced by the symbiont during the reproduction of the nematode in the insect. These antimicrobial compounds are believed to prevent the development of other bacteria in the insect cadaver. However, several reports have shown that there are occasionally bacteria other than the unique symbiont in the gut of nematodes. Lysenko \& Weiser (1974) isolated bacteria such as Alcaligenes, Pseudomonas and Acineto- 
bacter spp. from Steinernema carpocapsae. When S. carpocapsae was raised in the laboratory for extended periods (e.g. 15 years), bacteriological investigations indicated the presence of other associated bacteria such as Pseudomonas aureofaciens, Pseudomonas fluorescens, Enterobacter agglomerans and Serratia liquefaciens (Boemare, 1983). Similar observations were reported for Steinernema scapterisci, which was transferred from South America and subcultured many times in Florida. This nematode was associated with Ochrobactrum anthropi, Paracoccus denitrificans, Pseudomonas maltophilia and Xenorhabdus spp. (Aguillera et al., 1993; Aguillera \& Smart, 1993). Occasionally other Enterobacteriaceae were also isolated from Heterorhabditis spp. Thus, Jackson et al. (1995) showed that 10 out of 12 strains of Heterorhabditis were maintained in dixenic association with Photorhabdus spp. and Providencia rettgeri during laboratory storage.

The purpose of this study was to characterize naturally occurring bacteria often isolated in association with Photorhabdus luminescens from a large sampling of tropical Heterorhabditis spp. undertaken in the Caribbean basin (Constant et al., 1998). The H. bacteriophora collected in this area were very scarce, and consequently few examples of dixenic microbial associations were observed. They were not examined in this study. In contrast, H. indica was much more abundant and we observed dixenic microbial associations more frequently. Consequently, we undertook the identification of the isolates associated with Photorhabdus luminescens subsp. akhurstii, symbionts of $H$. indica (FischerLe Saux et al., 1999), by using conventional phenotypic tests, restriction fragment length polymorphism and sequence analyses of PCR-amplified 16S rRNA genes (16S rDNAs). In addition, we examined the entomopathogenicity and the antimicrobial activity of these isolates. All the data were collected to examine the biodiversity of the isolates throughout the Caribbean islands in comparison to the genotypic characterization and distribution of their associated symbiont P. luminescens subsp. akhurstii.

\section{METHODS}

Bacterial isolates. The origins of the bacterial strains are listed in Table 1. In addition, Micrococcus luteus CIP 5345 (Collection de l'Institut Pasteur) was used as an indicator of antibiosis. Nematodes were collected from different Caribbean islands and all isolates were identified to species level (Constant et al., 1998). The bacteria associated with infective juveniles were isolated by the hanging-drop technique (Poinar \& Thomas, 1966). A sterile drop of insect haemolymph was seeded with surface-disinfected infective juvenile nematodes (10 min in $10 \%, \mathrm{v} / \mathrm{v}$, fresh commercial sodium hypochlorite solution) and rinsed three times in sterile water. The microorganisms developing in the drop after $48 \mathrm{~h}$ at $28^{\circ} \mathrm{C}$ were streaked on MacConkey agar. Unknown bacteria associated with Photorhabdus symbiont phase I, which was found in all Heterorhabditis nematodes (Fischer-Le Saux et al., 1998), were repeatedly isolated on this medium. These Photorhabdus-associated isolates were designated by the suffix / sat and the phase I variant of the Photorhabdus symbiont was
Table 1. Photorhabdus-associated isolates and Photorhabdus strains used in this study

All isolates were from Heterorhabditis indica nematodes.

\begin{tabular}{|ll|}
\hline Strains & Geographical origin \\
\hline $\begin{array}{l}\text { Photorhabdus-associated isolates } \\
\text { Group Ia* }\end{array}$ \\
DO02/sat, DO07/sat, & Dominican Republic \\
DO09/sat, DO09H/sat, & \\
DO13/sat, DO21/sat, & \\
DO23/sat, DO24/sat & \\
Group Ib* & \\
PR17/sat, PR21/sat & Puerto Rico \\
Group II $\dagger$ & \\
FRG05/sat, FRG11/sat, & Guadeloupe \\
FRG19/sat, FRG33/sat & \\
Symbionts: Photorhabdus luminescens subsp. akhurstii $\neq$ \\
DO23/1 & Dominican Republic \\
PR17/1 & Puerto Rico \\
FRG11/1 & Guadeloupe \\
\hline
\end{tabular}

*In this study related to O. intermedium.

† In this study related to O. anthropi.

$\ddagger$ According to Fischer-Le Saux et al. (1999).

designated by the suffix /1. For instance, DO23/sat and DO23/1 were isolated from the nematode DO23.

Culture conditions. The optimal growth temperature was determined by streaking each isolate on nutrient agar plates and incubating at 28 and $37^{\circ} \mathrm{C}$. All the Photorhabdusassociated isolates grew better at $37^{\circ} \mathrm{C}$, and consequently all the biochemical tests described below were conducted at this temperature. Isolates were grown in Luria broth (LB) (DifcoFisher Scientific) on a shaking rack for $24 \mathrm{~h}$. The Photorhabdus-associated isolates were maintained on nutrient agar plates at $5^{\circ} \mathrm{C}$. P. luminescens strains DO23/1, PR $17 / 1$ and FRG11/1 were usually cultivated at $28{ }^{\circ} \mathrm{C}$ (but also at $37^{\circ} \mathrm{C}$, when mentioned). They were maintained on NBTA medium (nutrient agar supplemented with $25 \mathrm{mg}$ bromothymol blue $\mathrm{l}^{-1}$ and $40 \mathrm{mg}$ triphenyltetrazolium chloride $\mathrm{l}^{-1}$ ) at $15^{\circ} \mathrm{C}$ (Akhurst, 1980). In order to preserve all strains and isolates, a volume of each culture was mixed with sterile bi-distilled glycerol to a final concentration of $16 \%(\mathrm{v} / \mathrm{v})$ and kept frozen in liquid nitrogen.

Phenotypic characterization of the Photorhabdus-associated isolates. Phenotypic characterization was conducted according to Bergey's Manual (Holt et al., 1994), recent reports (Alnor et al., 1994; Holmes et al., 1988; Velasco et al., 1998), and additional tests summarized below. Colonial morphology was observed on nutrient agar and the diameter of colonies was measured after 24 and $48 \mathrm{~h}$ in five independent experiments. Dye adsorption on MacConkey agar or NBTA, and the test for bioluminescence, were conducted according to Boemare \& Akhurst (1988). The cell wall was characterized by the Gram enzymic test (Cerny, 1976). The distribution of flagella was determined according to Ryu (1937) and Kodaka et al. (1982), using the Bacto Spot Test Flagella Stain method (Difco). To assess spore formation, the Photorhabdus-associated isolates were grown in LB and incubated for $24 \mathrm{~h}$. Then 
cultures were incubated at $80{ }^{\circ} \mathrm{C}$ in a water bath for $10 \mathrm{~min}$ and reinoculated in $\mathrm{LB}$, followed by incubation at $37^{\circ} \mathrm{C}$ for $48 \mathrm{~h}$. The production of pyocyanin and pyoverdin fluorescent pigments was tested on King B and King A media, respectively (Difco). The respiratory type was determined on liver meat glucose $/ 0.6 \%(\mathrm{w} / \mathrm{v})$ agar (Biokar) with cultures incubated at $37^{\circ} \mathrm{C}$ for $24-36 \mathrm{~h}$. Other biochemical tests were conducted on API 20 NE strips and Biotype 100 strips for carbohydrate, amino acid and organic acid assimilation using the AUX medium from API $20 \mathrm{NE}$ as minimal medium (BioMérieux). All strips were incubated at $37^{\circ} \mathrm{C}$ and examined during $2 \mathrm{~d}$ for API $20 \mathrm{NE}$ and 1-5 d for Biotype 100. The methods of Boemare \& Akhurst (1988) were used to test lipolysis on Tween 20, 40, 60, 80 and 85. Haemolysis was determined on Tryptic Soy Agar (BioMérieux) supplemented with $10 \%$ (v/v) sterile defibrinated sheep blood (BioMérieux). DNase activity was tested on DNA agar medium (BioMérieux); after incubation, addition of $1 \mathrm{M} \mathrm{HCl}$ revealed clear zones around colonies when hydrolysis occurred.

Tests of susceptibility to antibiotics. For comparison with the results of Velasco et al. (1998) the susceptibility of Photorhabdus-associated bacteria to colistin and polymyxin $\mathrm{B}$ (Sigma; $7870 \mathrm{IU} \mathrm{mg}^{-1}$ ) was assessed on Mueller-Hinton agar using the standardized disk diffusion method with sterile disks loaded with 10 and $50 \mu \mathrm{g}$ antibiotic. The results were interpreted as sensitivity or resistance on the basis of the presence or absence of an inhibition halo, because there is no correlation between sensitivity and the diameter of the zone of inhibition for these antibiotics (Bauer et al., 1966). The antibacterial activity of $P$. luminescens subsp. akhurstii strains was tested in vitro against each Photorhabdus-associated isolate and the positive control M. luteus, as described by Akhurst (1982). Nutrient agar plates were spot-inoculated with $24 \mathrm{~h}$ broth cultures of the bacterial producer and incubated for $48 \mathrm{~h}$. Then plates were exposed to chloroform (30 $\mathrm{min})$ to kill spotted colonies. Plates were left for $30 \mathrm{~min}$ in a laminar-flow hood to allow evaporation of the chloroform. Sterile soft agar (100 ml containing $7 \mathrm{~g} \mathrm{agar}^{-1}$ ) was allowed to cool to $45^{\circ} \mathrm{C}$ before being inoculated with $1 \mathrm{ml}$ of $24 \mathrm{~h}$ old broth of the bacterial target. When mixed, it was poured on the previous plates. Growth inhibition around a spot indicated production of antibiotics by the bacterial producer and sensitivity of the bacterial target. The antibacterial activity of each Photorhabdus-associated isolate was determined in a similar way, by using M. luteus and P. luminescens strains as indicator bacteria.

Pathogenicity of Photorhabdus-associated isolates and Photorhabdus luminescens on Lepidoptera. Two Lepidoptera (L4 stage) were tested, Galleria mellonella and Spodoptera littoralis. Strains of Photorhabdus and of Photorhabdus-associated isolates were grown in $\mathrm{LB}(5 \mathrm{ml})$ for $18 \mathrm{~h}$ at $28^{\circ} \mathrm{C}$ and $37^{\circ} \mathrm{C}$, respectively. A $1 \mathrm{ml}$ sample of each culture was centrifuged in a microcentrifuge tube at $16000 \mathrm{~g}$ for $5 \mathrm{~min}$. The supernatant was removed and bacterial cells were washed twice in $1 \mathrm{ml}$ PBS buffer without $\mathrm{Ca}^{2+}$ and $\mathrm{Mg}^{2+}(134 \mathrm{mM} \mathrm{NaCl}, 2.68 \mathrm{mM}$ $\mathrm{KCl}, 76.9 \mathrm{mM} \mathrm{Na}_{2} \mathrm{HPO}_{4}, 1.47 \mathrm{mM} \mathrm{KH}_{2} \mathrm{PO}_{4}$ ) (Biochrom KG). Decimal dilutions of each final suspension in PBS buffer $(1 \mathrm{ml})$ were used for pathogenicity tests. Samples $(100 \mu \mathrm{l})$ of appropriate dilutions were spread on nutrient agar and incubated at $28^{\circ} \mathrm{C}$ or $37^{\circ} \mathrm{C}$ for $24-36$ h to determine c.f.u. Mortality was tested by injection of 20 surface-disinfected larvae with $20 \mu \mathrm{l}$ of each bacterial dilution or control PBS. Each injected larva was placed in a compartment of a well-ventilated plastic box incubated at room temperature (approx. $23^{\circ} \mathrm{C}$ ) for $6 \mathrm{~d}$. $G$. mellonella were fed with a mixture of wax, honey and gelatin, and S. littoralis were fed with corn paste. Mortality by feeding was determined by feeding $10 \mu \mathrm{l}$ of each bacterial dilution or control to fasted larvae $(24 \mathrm{~h})$ of $S$. littoralis. Mortality was noted every day and the $\mathrm{LD}_{50}$ was determined from $2 \mathrm{~d}$ to $6 \mathrm{~d}$ depending on the pathogenicity of the bacterial strain. Mortality was not recorded thereafter.

Nucleic acid extraction. Isolates were grown in LB $(5 \mathrm{ml})$ and incubated at $37^{\circ} \mathrm{C}$ on a shaking rack for $24 \mathrm{~h}$. DNA was extracted when an $\mathrm{OD}_{540} \geqslant 1.0$ was reached. Aliquots of each culture were dispensed into five microcentrifuge tubes $(1 \mathrm{ml})$ and centrifuged at $10000 \mathrm{~g}$ for $5 \mathrm{~min}$. Supernatants were removed and the pellets were washed twice with $200 \mu \mathrm{l}$ TE8 buffer $(50 \mathrm{mM}$ Tris/ $\mathrm{HCl}, 20 \mathrm{mM}$ EDTA, $\mathrm{pH} 8)$. The five bacterial suspensions were collected to obtain a final suspension of $1 \mathrm{ml}$. DNA extraction was performed with the MicroProbe IsoQuick Nucleic Acid Extraction Kit (ORCA Research) according to the rapid DNA-extraction protocol of the manufacturer. Finally, $100 \mu \mathrm{l}$ pure water was added to the DNA pellets, which were dissolved by incubation at $65^{\circ} \mathrm{C}$ for $1 \mathrm{~h}$. Suspensions were diluted 20- to 100-fold in TE10-1 buffer (Tris $10 \mathrm{mM}$, EDTA $1 \mathrm{mM}$; pH 8) to be used as templates for PCR.

PCR amplification of 16S rDNAs. PCR amplification was done as described by Brunel et al. (1997), with some modifications. The following two eubacterial-specific oligonucleotide primers (Eurogentec) were used: 5'-AAGGAGGTGATCCAGCCGCA-3' (antisense; E. coli numbering 1540-1521) and 5'GAAGAGTTTGATCATGGCTC-3' (sense; E. coli numbering 6-25) (Wiesburg et al., 1991). PCR conditions were optimized according to the basic protocol of the supplier of the DNA polymerase (GibcoBRL) and the PCR Applications Manual (Boehringer). The standard PCR mixtures $(50 \mu \mathrm{l})$ contained the following components, listed with their final concentration in autoclaved milliQ water: PCR buffer $(20 \mathrm{mM}$ Tris/ $\mathrm{HCl}, \mathrm{pH} 8 \cdot 4,50 \mathrm{mM} \mathrm{KCl}$ ) (GibcoBRL), 0.2 mM deoxynucleoside triphosphates (Pharmacia LKB), $1.75 \mathrm{mM} \mathrm{MgCl}_{2}$ (GibcoBRL), 0.4 $\mu \mathrm{M}$ of each primer, 2.5 U Taq DNA polymerase (GibcoBRL), and $1 \mu \mathrm{l}$ template DNA. The negative control contained all components of the PCR mixture except the template DNA. The reactions were run on a DNA thermal cycler GeneAmp PCR System 2400 (Perkin Elmer). The PCR programme comprised a 35 -cycle amplification series. After an initial denaturation at $94^{\circ} \mathrm{C}$ for $2 \mathrm{~min}$, each cycle included denaturation at $95{ }^{\circ} \mathrm{C}$ for $30 \mathrm{~s}$, annealing at $63{ }^{\circ} \mathrm{C}$ for $30 \mathrm{~s}$, and extension at $72^{\circ} \mathrm{C}$ for $1 \mathrm{~min}$. The final extension was carried out at $72{ }^{\circ} \mathrm{C}$ for $7 \mathrm{~min}$. The reaction products and the DNA Molecular Weight Marker II (Boehringer Mannheim) were separated in $1 \%(\mathrm{w} / \mathrm{v})$ agarose gel (Sigma) in TBE buffer ( $89 \mathrm{mM}$ Tris base, $89 \mathrm{mM}$ boric acid, $2 \mathrm{mM}$ EDTA; $\mathrm{pH} 8 \cdot 3$ ) (Interchim) by horizontal electrophoresis at $4 \mathrm{~V} \mathrm{~cm}^{-1}$. The gel was stained with ethidium bromide $\left(0.6 \mathrm{mg} \mathrm{l}^{-1}\right.$ in pure water $)$ for $10 \mathrm{~min}$, rinsed in pure water for 5-10 $\mathrm{min}$, visualized under UV light and photographed with a Polaroid MP-4 camera with Ilford 667 film (Polaroid).

RFLP of PCR-amplified 16S rDNAs. RFLP was done as described by Fischer-Le Saux et al. (1998). For each isolate, 6-17 $\mu$ l of amplified $16 \mathrm{rDNAs}$ were digested overnight at $37^{\circ} \mathrm{C}$ with $5 \mathrm{U}$ of four tetrameric restriction endonucleases: HinfI, HaeIII, MspI and CfoI (GibcoBRL). DNA digests and the DNA Molecular Weight Marker VIII (Boehringer) were analysed by horizontal electrophoresis at $4 \mathrm{~V} \mathrm{~cm}^{-1}$ in $3 \%(\mathrm{w} / \mathrm{v})$ Nusieve GTG gel (Tebu) in TBE buffer as described above for PCR amplification. Gels were visualized as described above.

Nucleotide sequencing of PCR-amplified 16S rDNAs. The PCR-amplified 16S rDNAs of DO23/sat, PR17/sat and FRG11/sat were sequenced. Amplified $16 \mathrm{~S}$ rDNAs were 
purified with the High Pure PCR Product Purification kit (Boehringer). Single-strand sequencing was performed by Act Gene Euro Sequence Gene Services (Genopole, Evry, France) using four primers: the two above-mentioned PCR primers and two others designed specifically to target the $16 \mathrm{~S}$ rRNA genes of Photorhabdus-associated isolates: PR153.1 (5' TAAACCACATGCTCCACC-3' : positions 940-957, E. coli numbering), and PR63.1 (5'-TTGTTCGGATTTACTGGG3': positions 550-567, E. coli numbering).

DNA sequence analysis. The three $16 \mathrm{~S}$ rDNA sequences obtained were compared to the EMBL database by using the algorithm BLAST2 (Altschul et al., 1997), in order to identify the most similar $16 \mathrm{~S}$ rDNA sequences. An alignment was performed, using the program PILEuP (Feng \& Doolittle, 1987), with a set of sequences of representatives of the most related genera identified. Pairwise comparisons of nucleic acid sequences were corrected for multiple base substitutions by the two-parameter method of Kimura (1980) using CLUSTAL-X (Thompson et al., 1997). A phylogenetic tree was constructed by the neighbour-joining method (Saitou \& Nei, 1987), and a bootstrap confidence analysis was performed on 1000 replicates to determine the reliability of the tree topology obtained (Felsenstein, 1985). Phylogenetic analyses were also performed, using the PHYLO_WIN software (Galtier et al., 1996), with parsimony (Kluge \& Farris, 1969) and maximumlikelihood (Felsenstein, 1981) methods.

\section{RESULTS}

\section{Isolation of Photorhabdus-associated bacteria from $H$. indica nematodes}

Two types of colony were isolated on MacConkey agar. One type adsorbed dye and the colonies were red and bioluminescent, with antibacterial activity. This first type of colony was identified as Photorhabdus luminescens subsp. akhurstii and was found in $100 \%(n=43)$ of the H. indica checked (Fischer-Le Saux et al., 1998, 1999). The second type did not adsorb dye and was characterized by non-bioluminescent, pink, round and bright dome-shaped colonies. The second type of colony (designated by the suffix /sat) was isolated with a frequency of about $33 \%(14 / 43)$. Eight of these 14

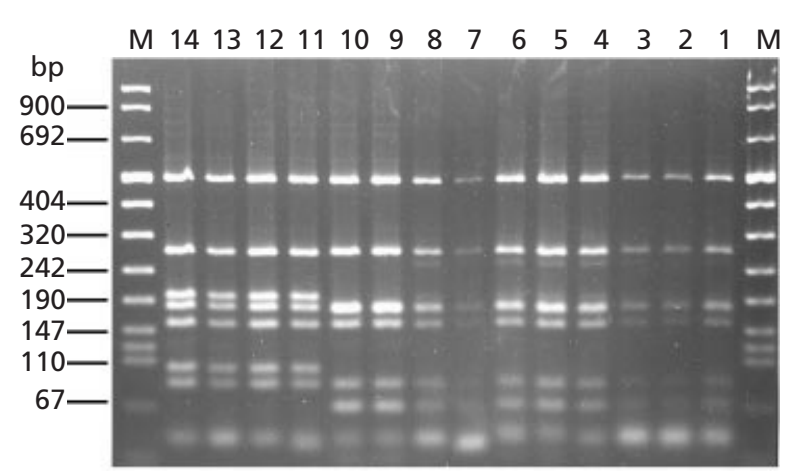

Fig. 1. Restriction patterns of $P C R$-amplified $16 \mathrm{~S}$ rRNA genes from all isolates cleaved by HaellI. Lanes M, Molecular Weight Marker VIII (Boehringer Mannheim); lanes 1-8, isolates DO/sat $(02,07,09,09 \mathrm{H}, 13,21,23$ and 24); lanes 9 and 10, isolates $\mathrm{PR} /$ sat (17 and 21); lanes 11-14, isolates FRG/sat (05, 11, 19 and 33).

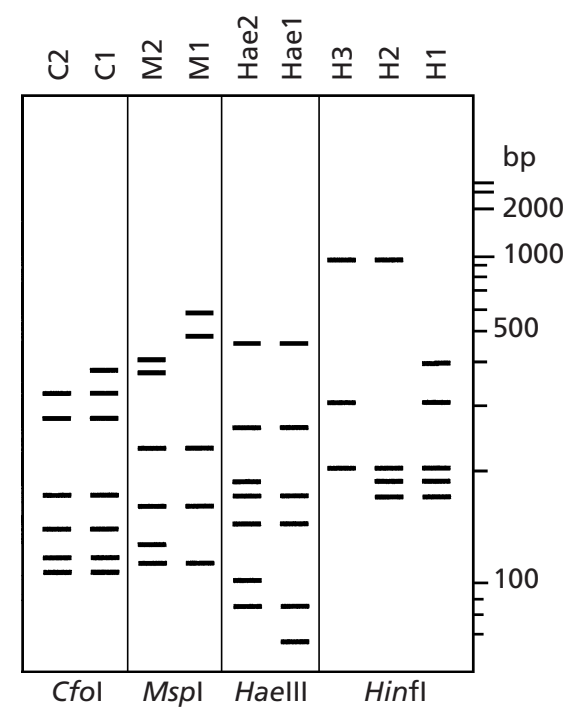

Fig. 2. Schematic restriction patterns of $P C R$-amplified 165 rRNA genes from Photorhabdus-associated isolates cleaved with four enzymes used in this study: Hinfl (H), Haelll (Hae), Mspl (M) and $\mathrm{Cfol}(\mathrm{C})$.

Photorhabdus-associated isolates were from the Dominican Republic (DO), four from Guadeloupe (FRG) and two from Puerto Rico (PR) (Table 1).

\section{PCR amplification and RFLP analysis of 16S rDNAs}

DNAs of all 14 isolates were amplified with the two specific eubacterial primers used; all produced a single fragment. All fragments were around $1550 \mathrm{bp}$, which was the size expected for $16 \mathrm{~S}$ rDNAs (data not shown). All the PCR-amplified 16S rDNAs were cleaved with the four tetrameric restriction endonucleases used. By combining all the restriction patterns obtained, the 14 Photorhabdus-associated isolates could be grouped into three genotypes, Ia, Ib and II. Genotypes Ia and Ib were very similar. Combinations of the restriction patterns were as follows: genotype Ia = H1, Hae1, M1 and C1; genotype $\mathrm{Ib}=\mathrm{H} 2$, Hae1, M1 and $\mathrm{C} 1$; genotype $\mathrm{II}=$ H3, Hae2, M2 and C2 (Figs 1 and 2). Thus genotypes Ia and Ib were only distinguished by Hinfl, while genotype II had a specific restriction pattern with each of the endonucleases used.

\section{Sequence analysis of PCR-amplified 16S rDNAs}

$16 \mathrm{~S}$ rDNA was sequenced for one isolate representative of each group: DO23/sat, PR17/sat and FRG11/sat. Partial sequences were obtained: 878, 1278 and $1214 \mathrm{bp}$ for DO23/sat, PR17/sat and FRG11/sat, respectively. Using the BLAST algorithm, $16 \mathrm{~S}$ rRNA genes of members of the $\alpha$-2 subdivision of Proteobacteria were identified as the most closely related sequences available in the EMBL gene database. Most of these $\alpha-2$ Proteobacteria belonged to the genera Ochrobactrum, Brucella, Bartonella, Mesorhizobium, Phyllobacterium, Mycoplana, Sinorhizobium, Agrobacterium and Rhizobium. 


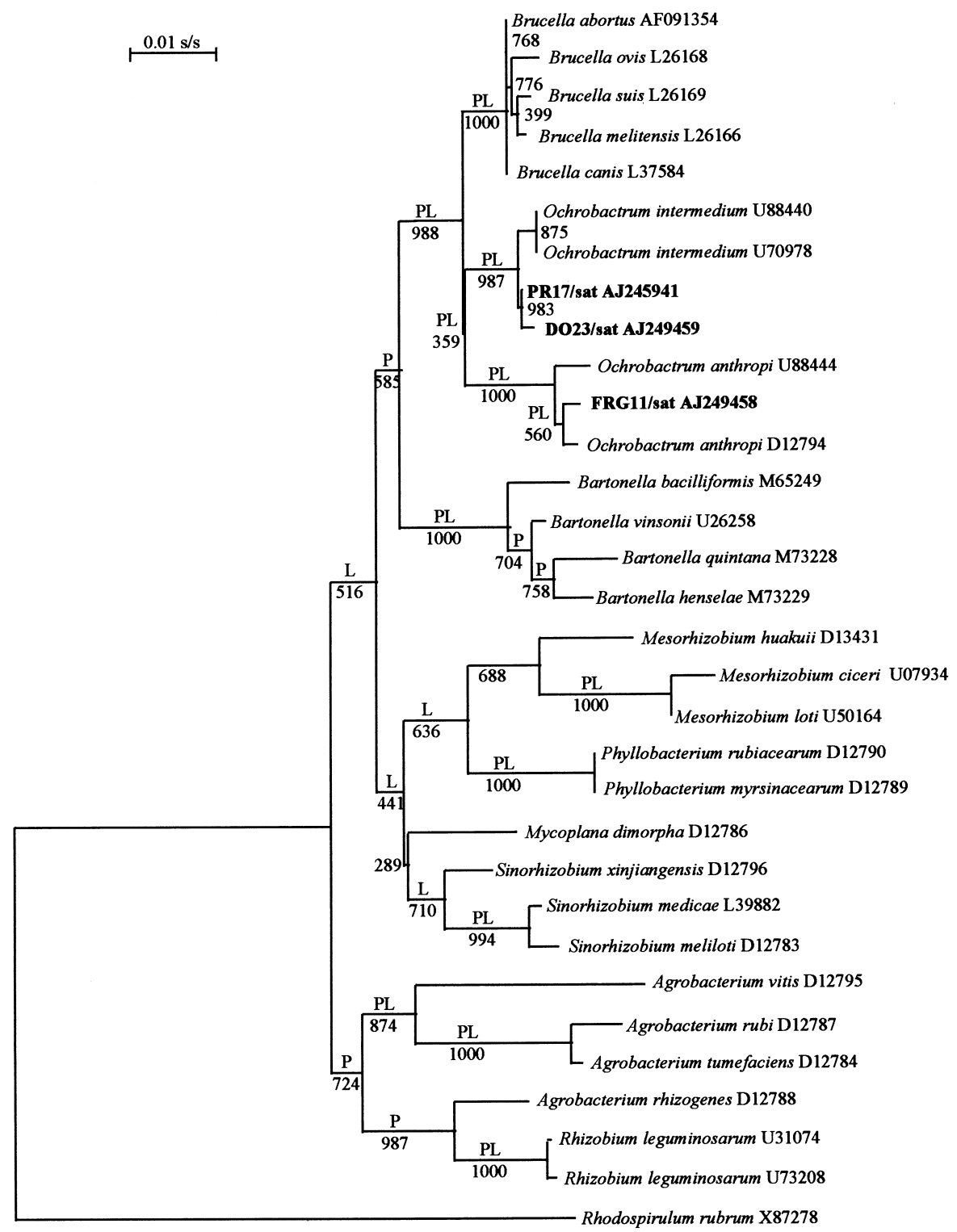

Fig. 3. Phylogenetic tree inferred from $16 \mathrm{~S}$ rDNA sequences analysis showing the relationships of Photorhabdusassociated isolates with several members of the $\alpha-2$ subdivision of Proteobacteria. The tree was constructed by the neighbour-joining method (Saitou \& Nei, 1987), using a bootstrap approach (Felsenstein, 1985) to determine the reliability of the topology (numbers given below the nodes). Those clusters also obtained by parsimony (Kluge $\&$ Farris, 1969) and by maximum-likelihood (Felsenstein, 1981) analyses are indicated by ' $P$ ' and ' $L$ ' above the nodes, respectively. The Rhodospirillum rubrum sequence was chosen as outgroup. Accession numbers are given after the species names. The scale bar represents 0.01 substitution per site $(\mathrm{s} / \mathrm{s})$.

The highest levels of identity were obtained with members of the genus Ochrobactrum: the 16S rDNA sequence of PR17/sat and DO23/sat had $>99 \%$ identity with Ochrobactrum intermedium (1276/1278 and $875 / 878 \mathrm{bp}$, respectively), and FRG11/sat had $>99 \%$ identity with Ochrobactrum anthropi (1209/ $1214 \mathrm{bp}$ ). Consequently, the $16 \mathrm{~S}$ rDNA sequences of the Photorhabdus-associated isolates were compared to $16 \mathrm{~S}$ rDNA sequences of representative species of the $\alpha-2$ subclass, particularly several strains of the genus Ochrobactrum. The phylogenetic tree obtained by the neighbour-joining method is shown in Fig. 3. The sequences determined in this study grouped with $16 \mathrm{~S}$ rDNA sequences of Ochrobactrum species. The sequences of PR17/sat and DO23/sat clustered together with sequences of $O$. intermedium strains LMG $3301^{\mathrm{T}}$ and LMG 3306, and the sequence of FRG11/sat with those of O. anthropi strains LMG 3331 ${ }^{\mathrm{T}}$ and LMG 2320. These clusters were supported by bootstrap values $\geqslant 98.7 \%$ and were confirmed by parsimony and maximum-likelihood analyses. Brucella species formed a tight cluster linked to Ochrobactrum species. Although the position of the O. intermedium group between the genus Brucella and O. anthropi strains was supported by 
a lower bootstrap value, the two genera formed a consistent cluster supported by a bootstrap value of $98.8 \%$ and by parsimony and maximum-likelihood analyses. Bootstrap confidence values for groups representing the other species included in the analysis were usually more than $70 \%$. Their clustering was in accordance with their genus assignation and with the results of the Ribosomal Dataset Project (RDP) Tree (Larsen et al., 1997).

Interestingly, the $16 \mathrm{~S}$ rDNA genotypic polymorphism and the corresponding sequence analysis were strictly correlated with the geographical origin of the isolates. All the isolates from the Dominican Republic were of genotype Ia, all the isolates from Puerto Rico were of genotype $\mathrm{Ib}$, and all the isolates from Guadeloupe were of genotype II.

\section{Phenotypic characters}

All the Photorhabdus-associated isolates were characterized as Gram-negative non-spore-forming rods, motile with polar flagella, non-bioluminescent, non-fluorescent on King A and King B media, oxidase- and catalase-positive, reducing nitrate to nitrite (in some cases to nitrogen), obligatorily aerobic and possessing a strictly oxidative metabolism. The optimal growth temperature determined on nutrient agar was $37^{\circ} \mathrm{C}$. Colonies had a dome-round shape, a bright white-beige colour, looked slippery and opaque on nutrient agar, were red on NBTA medium, and grew on MacConkey agar. All strains were positive for the Simmons' citrate test. Seven tests were recorded as negative for all strains : Voges-Proskauer reaction, hydrogen sulfide and indole production, and $\beta$-galactosidase, lysine decarboxylase, ornithine decarboxylase and arginine dihydrolase activities. The following eight exoenzymic activities were also negative for all the isolates: gelatin (Kohn's) hydrolysis, Tween 20, 40, 60, 80 and 85 hydrolysis, DNase, and haemolysis on sheep blood agar.

All the Photorhabdus-associated isolates used the following as sole source of carbon: adonitol, aesculin, D-alanine, L-alanine, (+)-L-arabinose, (+)-D-arabitol, L-aspartate, betaine, DL- $\alpha$-amino-n-butyrate, citrate, dulcitol, erythritol, (+)- $\beta$-D-fructose, (-)- $\alpha$-L-fucose, fumarate, (+)-D-galactose, D-galacturonate, gluconate, 2-keto-D-gluconate, D-glucuronate, $\mathrm{N}$-acetyl-D-glucosamine, (+)-D-glucose, $\alpha$-L-glutamate, 2-oxoglutarate, DL-lactate, (+)-D-malate, (-)-L-malate, maltitol, maltose, maltotriose, (+)-D-mannose, L-proline, propionate, protocatechuate, $\alpha$-L-rhamnose, L-serine, succinate, sucrose, D-tagatose and (+)-D-turanose.

They were all negative for assimilation of phenylacetate, (-)-L-arabitol, benzoate, 3-hydroxybenzoate, caprylate, $m$-coumarate, 1-O-methyl $\alpha$-galactopyranoside, 1-O-methyl $\beta$-galactopyranoside, gentisate, 5-keto-Dgluconate, 3-O-methyl D-glucopyranose, 1-O-methyl $\alpha$-D-glucopyranoside, hydroxyquinoline- $\beta$-glucuronide, histamine, L-histidine, itaconate, $\alpha$-lactose, lactulose, malonate, (+)-D-melezitose, (+)- $\alpha$-D-melibiose,
Table 2. Phenotypic characters distinguishing Photorhabdus-associated isolates

All tests were done at $37 \pm 1{ }^{\circ} \mathrm{C}$. Number of isolates: 8 for group Ia; 2 for group Ib; 4 for group II. +, 90-100\% of strains positive; [+], 76-89\% positive; $\mathrm{d}, 26-75 \%$ positive; [- ], $11-25 \%$ positive;,$- 0-10 \%$ positive. The superscript $w$ (e.g. $[+]^{\mathrm{w}}$ ) indicates a weak reaction. For sensitivity tests: R, 90-100\% resistant; [R], 76-89\% resistant; S, 90-100\% sensitive; [S], 76-89\% sensitive; $d, 26-75 \%$ resistant. The most discriminatory characters are shown in bold.

\begin{tabular}{|c|c|c|c|}
\hline & $\begin{array}{c}\text { Group } \\
\text { Ia }\end{array}$ & $\begin{array}{c}\text { Group } \\
\text { Ib }\end{array}$ & $\begin{array}{c}\text { Group } \\
\text { II }\end{array}$ \\
\hline \multicolumn{4}{|l|}{ Sensitivity to: } \\
\hline Colistin & {$[\mathrm{S}]$} & $\mathrm{d}$ & S \\
\hline Polymyxin B & {$[\mathrm{R}]$} & $\mathrm{R}$ & $S$ \\
\hline P. l. akhurstii antibiotics & $\mathrm{R}$ & $\mathrm{R}$ & $S$ \\
\hline Urease & $\mathrm{d}$ & + & + \\
\hline Aesculin hydrolysis & $\mathrm{d}$ & $\mathrm{d}$ & {$[+]$} \\
\hline \multicolumn{4}{|l|}{ Assimilation of: } \\
\hline cis-Aconitate & + & $\mathrm{d}$ & {$[+]^{\mathrm{w}}$} \\
\hline trans-Aconitate & - & - & {$[+]^{\mathrm{w}}$} \\
\hline 4-Hydroxybenzoate & + & + & $\mathrm{d}$ \\
\hline DL- $\beta$-Hydroxybutyrate & + & $\mathrm{d}$ & $\mathrm{d}$ \\
\hline Caprate & + & + & $\mathrm{d}$ \\
\hline (+)-D-Cellobiose & + & + & {$[-]$} \\
\hline Ethanolamine & {$[+]$} & $d^{w}$ & {$[-]$} \\
\hline$\beta$-Gentiobiose & + & + & - \\
\hline Methyl $\beta$-D-glucopyranoside & + & + & - \\
\hline D-Glucosamine & {$[+]$} & - & - \\
\hline Glutarate & + & + & $\mathrm{d}$ \\
\hline DL-Glycerate & {$[+]$} & $+{ }^{w}$ & + \\
\hline Glycerol & $+\mathrm{w}$ & $\mathrm{d}$ & + \\
\hline myo-Inositol & + & + & {$[+]$} \\
\hline D-Lyxose & {$[+]$} & $\mathrm{d}$ & {$[+]^{\mathrm{w}}$} \\
\hline D-Mannitol & {$[+]$} & + & + \\
\hline Palatinose & + & $\mathrm{d}$ & $+{ }^{\mathrm{w}}$ \\
\hline Quinate & + & $\mathrm{d}$ & + \\
\hline$(-)$-D-Ribose & + & $\mathrm{d}$ & $\mathrm{d}$ \\
\hline D-Sorbitol & + & + & - \\
\hline$(+)$-D-Trehalose & + & $\mathrm{d}$ & $+{ }^{\mathrm{w}}$ \\
\hline 5-Aminovalerate & {$[+]$} & $\mathrm{d}$ & {$[+]$} \\
\hline$(+)$-D-Xylose & + & $\mathrm{d}$ & + \\
\hline
\end{tabular}

mucate, 3-phenylpropionate, putrescine (diaminobutane), (+)-D-raffinose, D-saccharate, (+)-L-sorbose, $(-)$-D-tartrate, (+)-L-tartrate, meso-tartrate, tricarballytate, trigonelline, tryptamine, L-tryptophan, Ltyrosine and xylitol.

Differential characters between isolates are given in Table 2. Urease and aesculin hydrolyses were variable according to the isolates. Most of the Photorhabdusassociated isolates of group Ia and about half of group $\mathrm{Ib}$ were sensitive to colistin. Most of the group Ia and all of the group $\mathrm{Ib}$ isolates were resistant to polymyxin $\mathrm{B}$, and this was independent of the concentration (10 and $50 \mu \mathrm{g}$ ). All of the group II isolates were sensitive to both 
antibiotics. After the same time of incubation $(48 \mathrm{~h})$ of the Photorhabdus producers DO23/1, PR17/1 and FRG11/1, isolates of group I were scored as resistant to Photorhabdus antibiotics whereas isolates of group II were all sensitive. Isolates of group I, the $16 \mathrm{~S}$ rRNA sequence from which strongly aligned with those of $O$. intermedium, used $(+)$-D-cellobiose, $\beta$-gentiobiose, 1 $O$-methyl $\beta$-D-glucopyranoside and D-sorbitol as sole source of carbon. In contrast, isolates of group II, which clustered with $\mathrm{O}$. anthropi in $16 \mathrm{~S}$ rRNA sequence analysis, did not use these substrates but weakly assimilated trans-aconitate. Both groups had variable responses for cis-aconitate, 4-hydroxybenzoate, DL- $\beta$ hydroxybutyrate, caprate, ethanolamine, $(+)$-D-glucosamine, glutarate, DL-glycerate, glycerol, myo-inositol, D-lyxose, D-mannitol, palatinose, quinate, $(-)$-D-ribose, $(+)$-D-trehalose, 5-aminovalerate and (+)-D-xylose.

\section{Entomopathogenicity of Photorhabdus-associated isolates and $\boldsymbol{P}$. luminescens subsp. akhurstii to Lepidoptera}

Pathogenicity to insects was studied with the pair DO23/sat (Ochrobactrum) and DO23/1 (Photorhabdus) on two Lepidoptera, G. mellonella and $S$. littoralis, using injection and feeding tests. Isolate DO23/sat was not pathogenic to the two species of insect in the injection test: the lethal population that killed $50 \%\left(\mathrm{LD}_{50}\right)$ was $\geqslant 6 \times 10^{5}$ bacteria for G. mellonella and $\geqslant 3.5 \times 10^{6}$ bacteria for $S$. littoralis. In contrast, the $\mathrm{LD}_{50}$ of the symbiont DO23/1 was $\leqslant 30$ bacteria for G. mellonella and $\leqslant 45$ bacteria for $S$. littoralis. No pathogenicity of DO23/1 or DO23/sat to S. littoralis was detected with the feeding test. Similar experiments were conducted to test PR17/1 and PR17/sat, and FRG11/1 and FRG11/sat, on $S$. littoralis and $G$. mellonella by a faster process using dilutions from which the number of bacterial cells was only evaluated microscopically with a Thoma cell counter. $\mathrm{LD}_{50}$ values were recorded as $\geqslant 10^{5}$ bacterial cells for Photorhabdusassociated bacteria, and as $\leqslant 100$ cells for Photorhabdus symbionts.

\section{DISCUSSION}

Our study showed that bacteria associated with the symbiont Photorhabdus luminescens subsp. akhurstii and isolated from tropical $H$. indica nematodes had phenotypic characteristics and $16 \mathrm{~S}$ rRNA genes very similar to those of Ochrobactrum spp. The main phenotypic characteristics of isolates, enzymic activities and carbohydrate assimilation tests are identical to those of the genus Ochrobactrum (Alnor et al., 1994; Holmes et al., 1988; Holt et al., 1994; Velasco et al., 1998). They were Gram-negative non-spore-forming rods, motile with polar flagella, oxidase and catalasepositive, reducing nitrate to nitrite (in some cases beyond nitrite, as mentioned for O. anthropi), and possessed a strictly oxidative metabolism. All positive and negative characters mentioned in the Results are in agreement with the previous descriptions of Ochrobactrum spp. except hydrogen sulfide production, which was negative in all our isolates whereas it was reported as positive for O. intermedium and variable for O. anthropi. Moreover, urease, which was reported as positive for all the Ochrobactrum spp. described, was variable in our isolates. Using a total of 100 substrates, results of assimilation of purified organic compounds on minimal medium were in agreement with most of the results reported by Holmes et al. (1988). Adonitol, arabinose, glucose, mannose, L-rhamnose and sucrose were assimilated by all the Photorhabdus-associated isolates. These results are in agreement with Holmes et al. (1988) and in contradiction with those of Velasco et al. (1998). However, we obtained some negative results for the assimilation of glycerol, inositol, mannitol and sorbitol, as reported by Velasco et al. (1998).

The 14 Photorhabdus-associated isolates fell into three genotype groups, Ia, Ib and II. Groups Ia and Ib differed from each other in only one of four restriction enzyme patterns, while group II had a specific pattern with each of the four restriction enzymes used. Isolates of group I were variable in their susceptibility to colistin, but most of the group II isolates were resistant to polymyxin B. We recognized, mainly in the case of polymyxin $\mathrm{B}$, antibiotic sensitivity of group II and resistance of group I, as was reported by Velasco et al. (1998) for medical strains of O. anthropi (sensitive) and O. intermedium (resistant). The same feature was noticed for the action of antibiotics produced by $P$. luminescens subsp. akhurstii: group I is resistant and group II is susceptible. For O. intermedium, it was suggested that the resistance to polymyxin B is due to a difference in the cell wall (Velasco et al., 1998). Groups I and II can be also be easily distinguished by four substrate-assimilation characters, while subgroups Ia and Ib have variable responses depending on the substrate (Table 2). A notable exception was aesculin hydrolysis, which was variable for the Photorhabdus-associated isolates of group I, while most of group II was positive. O. anthropi was reported as negative for this test (Holmes et al., 1988) and $O$. intermedium as variable (Velasco et al., 1998).

$16 \mathrm{~S}$ rDNA sequence comparisons revealed that the Photorhabdus-associated bacteria clustered with members of the $\alpha-2$ subclass of Proteobacteria. A phylogenetic analysis including different representative species of this group and based on three different methods showed the clustering of Photorhabdus-associated bacteria with Ochrobactrum strains (results supported by high bootstrap values). The close phylogenetic relationships between the genera Brucella and Ochrobactrum previously described (Romero et al., 1995; Yanagi \& Yamasato, 1993) was confirmed. Recently, a new species of Ochrobactrum was proposed by Velasco et al. (1998) based on DNA-DNA hybridization values, Western blots and 16S rRNA gene analyses. This species was named $O$. intermedium for its intermediate position between O. anthropi and Brucella spp. This segregation of Ochrobactrum strains was confirmed in our phylogenetic analyses, where they formed two separate clusters corresponding to the two described species. 
Representatives of both species were identified among Photorhabdus-associated bacteria: PR17/sat from Puerto Rico and DO23/sat from the Dominican Republic grouped with $O$. intermedium strains, whereas FRG11/sat from Guadeloupe grouped with O. anthropi strains. Moreover, the sequence signature of $\mathrm{O}$. intermedium described by Velasco et al. (1998) was found in PR17/sat and DO23/sat sequences but not in the FRG11/sat sequence.

Thus, the $16 \mathrm{~S}$ rDNA PCR-RFLP and sequencing results are in accordance. Genotypes Ia and Ib, which were closely related, and only discriminated by HinfI patterns, correspond to isolates of O. intermedium, and genotype II, which was more divergent, with four specific restriction patterns, corresponds to isolates of O. anthropi. The three genotypes were isolated from nematodes obtained from three different geographical locations. All the isolates from the Dominican Republic were of genotype Ia, all the isolates from Puerto Rico of genotype $\mathrm{Ib}$, and all the isolates from Guadeloupe of genotype II. Consequently, the biodiversity of the Photorhabdus-associated bacteria is related to their geographical origin in the Caribbean basin, whereas Fischer-Le Saux et al. (1998) showed that the biodiversity of the corresponding Photorhabdus symbiont is only related to the host nematode. Consequently, there is not the co-speciation shown for the Photorhabdus/ Heterorhabditis pair (Fischer-Le Saux et al., 1999). The association of Photorhabdus-associated isolates with $H$. indica is not symbiotic, explaining the observation that they were isolated in only $33 \%$ of the samples. None of the representative strains of each group were pathogenic for lepidopteran insects. Evidently Heterorhabditis nematodes offer an occasional habitat for some species of Ochrobactrum, as mentioned for Steinernema scapterici (Aguillera et al., 1993; Bonifassi et al., 1999).

The presence of a second bacterium living together with the natural symbiont in $33 \%$ of the Carribean samples of Heterorhabditis is noteworthy. This new bacterial associate is easy to discriminate by simple bacteriological tests (oxidase- and nitrate-reductase-positive, oxidative metabolism) from the previous reports of secondary development of Photorhabdus variants (Wouts, 1990), occurrence of small colony variants ( $\mathrm{Hu}$ \& Webster, 1998), or existence of intermediate forms of phase variant (Gerritsen et al., 1995). Our concern is the origin of these bacteria identified as Ochrobactrum. In this study, the isolates came directly from native nematodes freshly harvested without any laboratory transfer. The fact that we distinguished three different groups of Ochrobactrum by $16 \mathrm{~S}$ rDNA and phenotypic properties, the first one being isolated in the Dominican Republic, the second in Puerto Rico and the third in Guadeloupe, eliminates any suspicion of a general contamination resulting from the bacterial isolation method. However, the question arises, in what part of the nematodes are these bacteria carried? Are they located (1) on the external cuticle, (2) in the space between the two cuticles L2 and L3 occurring on infective juveniles, or (3) in the nematode gut? The disinfection of nematodes with sodium hypochlorite, as performed by Fischer-Le Saux et al. (1998), eliminates hypothesis (1), but hypothesis (2) remains plausible. The presence of contaminating bacteria between the two cuticles was previously shown in Steinernema scapterisci (Bonifassi et al., 1999), and it was demonstrated that the removal of the old cuticle L2 from L3 larvae during the disinfection with sodium hypochlorite solution was absolutely necessary to eliminate such contaminants. Heterorhabditis are more difficult to exsheath and consequently the old L2 cuticle is more tightly associated with the cuticle of L3 larvae. Hence the presence of bacteria between the sheath and the cuticle, especially in the mid-body region, where such a space is more prominent, is a strong possibility. Because during the collection of the isolates reported here, the exsheathing of all L3 was not systematically controlled during the external disinfection of L3, we cannot eliminate hypothesis (2). Therefore, the Ochrobactrum spp. may be located in a cryptic space between the sheath and cuticle of the integument (hypothesis 2) or in the intestinal tract of L3 larvae (hypothesis 3). In situ hybridization using a specific $16 \mathrm{~S}$ rDNA probe for Ochrobactrum should be performed on tissues of Heterorhabditis to confirm where the associated bacteria are located in the nematode. Otherwise it would be too difficult to recognize the location of the bacteria due to the size $(500-800 \mu \mathrm{m})$ of Heterorhabditis infective juveniles.

The natural occurrence of both Photorhabdus and Ochrobactrum in H. indica is of interest in terms of a possible function in interaction with the host. According to Bucher (1960), a bacterium was characterized as pathogenic for insects when the $\mathrm{LD}_{50}$ is $\leqslant 10^{4}$ inoculated bacteria. By this criterion, the representative isolates of Photorhabdus-associated bacteria were not entomopathogenic, whereas Photorhabdus luminescens subsp. akburstii strains were. Could the Ochrobactrum spp. play a role in the reproductive cycle of the nematode in the insects? Schafer et al. (1996) showed that an Ochrobactrum sp. was a symbiotic bacterium of the termite gut which was involved in the degradation of hemicellulose. Therefore, we can postulate that $O$. intermedium-related isolates of group I found in $H$. indica nematodes might play a nutritional role when both genera can multiply together in the insect host. In contrast, the fact that $O$. anthropi-related isolates of group II are susceptible to the antibiotics of the corresponding symbiont (Table 2) would exclude such cohabitation in the insect during parasitism. The conclusion that these bacteria are occasionally present in the nematodes without any role in the association is therefore reasonable.

By examining the bacteriological safety of the mass production of Heterorhabditis for biological control, it was assessed that Photorhabdus symbionts were nonpathogenic for humans under normal conditions (Poinar et al., 1982), as was also determined for the five known clinical strains of non-symbiotic Photorhabdus (Farmer et al., 1989). A similar question may be asked for the Photorhabdus-associated isolates of this study, where 
similarities with micro-organisms of medical importance can be recognized. O. anthropi occurs as an opportunistic bacterium in human specimens (Alnor et al., 1994; Chester \& Cooper, 1979; Christenson et al., 1997; Holmes et al., 1988; Kern et al., 1993), often acquired in critically ill or immunosupressed patients with or without indwelling catheters (Cieslak et al., 1996; Gill et al., 1997; Yu et al., 1998). More recently, Moller et al. (1999) reported a case of infection due to the new species O. intermedium. In this context, the isolation of bacteria characterized as Ochrobactrum spp. and associated with the natural symbiont $P$. luminescens subsp. akhurstii in the entomopathogenic nematode $H$. indica from the Caribbean basin suggests that we should be vigilant. Since these associated bacteria are similar to nosocomial bacteria, a mass production of entomopathogenic nematodes should be strictly controlled to prevent any contamination. As previously claimed by Boemare et al. (1996), monoxenic nematodes obtained from the combination of surfaceaxenized eggs with the natural symbiont should be used for this purpose. Microbial populations should be controlled in all steps of the industrial process in order to ensure workers' safety and deliver a well-defined final product in terms of bacteria and nematodes.

\section{ACKNOWLEDGEMENTS}

We thank F. Cousserans, C. Laroui and S. Pagès for their technical assistance, and M. Patel (Imperial College, UK) for his nematological advice.

\section{REFERENCES}

Aguillera, M. M. \& Smart, G. C., Jr (1993). Development, reproduction, and pathogenicity of Steinernema scapterisci in monoxenic culture with different species of bacteria. J Invertebr Pathol 62, 289-294.

Aguillera, M. M., Hodge, N. C., Stall, R. E. \& Smart, G. C., Jr (1993). Bacterial symbionts of Steinernema scapterisci. J Invertebr Pathol 62, 68-72.

Akhurst, R. J. (1980). Morphological and functional dimorphism in Xenorhabdus spp., bacteria symbiotically associated with the insect pathogenic nematodes Neoaplectana and Heterorhabditis. J Gen Microbiol 121, 303-309.

Akhurst, R. J. (1982). Antibiotic activity of Xenorhabdus spp., bacteria symbiotically associated with insect pathogenic nematodes of the families Heterorhabditidae and Steinernematidae. J Gen Microbiol 128, 3061-3065.

Akhurst, R. J. \& Boemare, N. E. (1988). A numerical taxonomic study of the genus Xenorhabdus (Enterobacteriaceae) and proposed elevation of the subspecies of X. nematophilus to species. J Gen Microbiol 134, 1835-1845.

Akhurst, R. J., Mourant, R. G., Baud, L. \& Boemare, N. E. (1996). Phenotypic and DNA relatedness study between nematode symbionts and clinical strains of the genus Photorhabdus (Enterobacteriaceae). Int J Syst Bacteriol 46, 1034-1041.

Alnor, D., Frimodt-Moller, N., Espersen, F. \& Frederiksen, W. (1994). Infections with the unusual human pathogens Agrobacterium species and Ochrobactrum anthropi. Clin Infect Dis 18, 914-920.

Altschul, S. F., Madden, T. L., Schäffer, A. A., Zhang, J., Zhang, Z.,
Miller, W. \& Lipman, D. J. (1997). Gapped BLAST and PSI-BLAST : a new generation of protein database search programs. Nucleic Acids Res 25, 3389-3402.

Bauer, A. W., Kirby, W. M. M., Sherris, J. C. \& Turck, M. (1966). Antibiotic susceptibility testing by a standardized single disk method. Am J Clin Pathol 45, 493-496.

Boemare, N. E. (1983). Recherches sur les complexes nématobactériens entomopathogènes: étude bactériologique, gnotobiologique et physiopathologique du mode d'action parasitaire de Steinernema carpocapsae Weiser (Rhabitida: Steinernematidae). Thèse d'Etat (PhD thesis), Université Montpellier II.

Boemare, N. E. \& Akhurst, R. J. (1988). Biochemical and physiological characterization of colony form variants in Xenorhabdus spp. (Enterobacteriaceae). J Gen Microbiol 134, 751-761.

Boemare, N. E., Akhurst, R. J. \& Mourant, R. G. (1993). DNA relatedness between Xenorhabdus spp. (Enterobacteriaceae), symbiotic bacteria of entomopathogenic nematodes, and a proposal to transfer Xenorhabdus luminescens to a new genus, Photorhabdus gen. nov. Int J Syst Bacteriol 43, 249-255.

Boemare, N. E., Laumond, C. \& Mauléon, H. (1996). The nematode-bacterium complexes: biology, life cycle, and vertebrate safety. Biocontrol Sci Technol 6, 333-345.

Boemare, N. E., Givaudan, A., Brehélin, M. \& Laumond, C. (1997). Symbiosis and pathogenicity of nematode-bacterium complexes. Symbiosis 22, 21-45.

Bonifassi, E., Fischer-Le Saux, M., Boemare, N., Lanois, A., Laumond, C. \& Smart, G. (1999). Gnotobiological study of infective juveniles and symbionts of Steinernema scapterisci: a model to clarify the concept of the natural occurrence of monoxenic associations in entomopathogenic nematodes. $J$ Invertebr Pathol 74, 164-172.

Brunel, B., Givaudan, A., Lanois, A., Akhurst, R. J. \& Boemare, N. (1997). Fast and accurate identification of Xenorhabdus and Photorhabdus species by restriction analysis of PCR-amplified 16S rRNA genes. Appl Environ Microbiol 63, 574-580.

Bucher, G. E. (1960). Potential bacterial pathogens of insects and their characteristics. J Insect Pathol 2, 172-195.

Cerny, G. (1976). Method for distinction of Gram positive from Gram negative bacteria. J Appl Microbiol 3, 223-225.

Chester, B. \& Cooper, L. H. (1979). Achromobacter species (CDC group $\mathrm{Vd}$ ): morphological and biochemical characterization. $J$ Clin Microbiol 9, 425-436.

Christenson, J. C., Pavia, A. T., Seskin, K., Brockmeyer, D., Korgenski, E. K., Jenkins, E., Pierce, J. \& Daly, J. A. (1997). Meningitis due to Ochrobactrum anthropi: an emerging nosocomial pathogen. A report of 3 cases. Pediatr Neurosurg 27, 218-221.

Cieslak, T. J., Drabick, C. J. \& Robb, M. L. (1996). Pyogenic infections due to Ochrobactrum anthropi. Clin Infect Dis 22, 845-847.

Constant, P., Marchay, L., Fischer-Le Saux, M., Briand-Panoma, S. \& Mauléon, H. (1998). Natural occurrence of entomopathogenic nematodes (Rhabditida: Steinernematidae and Heterorhabditidae) in Guadeloupe islands. Fundam Appl Nematol 21, 667-672.

Farmer, J. J., Jorgensen, J. H., Grimont, P. A. D. \& 8 other authors (1989). Xenorhabdus luminescens (DNA hybridization group 5) from human clinical specimens. J Clin Microbiol 27, 1594-1600.

Felsenstein, J. (1981). Evolutionary trees from DNA sequences: a maximum likelihood approach. J Mol Evol 17, 368-376.

Felsenstein, J. (1985). Confidence limits on phylogenies: an approach using the bootstrap. Evolution 39, 783-791. 
Feng, D. J. \& Doolittle, R. F. (1987). Progressive sequence alignment as a prerequisite to correct phylogenetic trees. J Mol Evol 25, 351-360.

Fischer-Le Saux, M., Mauleon, H., Constant, P., Brunel, B. \& Boemare, N. (1998). PCR-ribotyping of Xenorhabdus and Photorhabdus isolates from the Caribbean region in relation to the taxonomy and geographic distribution of their nematode hosts. Appl Environ Microbiol 64, 4246-4254.

Fischer-Le Saux, M., Viallard, V., Brunel, B., Normand, P. \& Boemare, N. (1999). Polyphasic classification of the genus Photorhabdus and proposal of new taxa: P. luminescens subsp. luminescens subsp. nov., P. luminescens subsp. akhurstii subsp. nov., P. luminescens subsp. laumondii subsp. nov., P. temperata sp. nov., $P$. temperata subsp. temperata subsp. nov. and $P$. asymbiotica sp. nov. Int J Syst Bacteriol 49, 1645-1656.

Galtier, N., Gouy, M. \& Gautier, C. (1996). Sea View and PHYLO_WIN, two graphic tools for sequence alignment and molecular phylogeny. Comput Appl Biosci 12, 543-548.

Gaugler, R. \& Kaya, H. K. (1990). Entomopathogenic Nematodes in Biological Control. Boca Raton, FL: CRC Press.

Gerritsen, L. J. M., Van der Wolf, J. M., Van Vuurde, J. W. L., Ehlers, R.-U., Krasomil-Osterfeld, K. C. \& Smits, P. H. (1995). Polyclonal antisera to distinguish strains and form variants of Photorhabdus (Xenorhabdus) luminescens. Appl Environ Microbiol 61, 284-289.

Gill, M. V., Ly, H., Mueenuddin, M., Schoch, P. E. \& Cunha, B. A. (1997). Intravenous line infection due to Ochrobactrum anthropi (CDC Group Vd) in a normal host. Heart Lung 26, 335-336.

Holmes, B., Popoff, M., Kiredjian, M. \& Kersters, K. (1988). Ochrobactrum anthropi gen. nov., sp. nov. from human clinical specimens and previously known as Group Vd. Int J Syst Bacteriol 38, 406-416.

Holt, J. G., Krieg, N. R., Sneath, P. A., Staley, J. T. \& Williams, S. T. (1994). Bergey's Manual of Determinative Bacteriology, 9th edn. Baltimore: Williams \& Wilkins.

Hu, K. \& Webster, J. M. (1998). In vitro and in vivo characterization of a small-colony variant of the primary form of Photorhabdus luminescens MD (Enterobacteriaceae). Appl Environ Microbiol 64, 3214-3219.

Jackson, T. J., Wang, H., Nugent, M. J., Griffin, C. T., Burnell, A. M. \& Dowds, B. C. A. (1995). Isolation of insect pathogenic bacteria, Providencia rettgeri, from Heterorhabditis spp. J Appl Bacteriol 78, 237-244.

Kern, W. V., Oethinger, M., Kaufhold, A., Rozdzinski, E. \& Marre, R. (1993). Ochrobactrum anthropi bacteremia: report of four cases and short review. Infection 21, 306-310.

Kimura, M. (1980). A simple method for estimating evolutionary rates of base substitutions through comparative studies of nucleotide sequences. J Mol Evol 16, 111-120.

Kluge, A. G. \& Farris, J. S. (1969). Quantitative phyletics and the evolution of anurans. Syst Zool 18, 1-32.

Kodaka, H., Armfield, A. Y., Lombard, G. L. \& Dowell, V. R. (1982). Practical procedure for demonstrating bacterial flagella. $J$ Clin Microbiol 16, 948-952.

Larsen, N., Overbeek, R., Harrison, S., Searles, D. \& Garrity, G. (1997). Bergey's Revision of the RDP Tree. In http://
www.cme.msu.edu/Bergeys/btcomments/bt9.pdf, pp. 49-50. Edited by J. Garrity \& S. Harrison. Baltimore: Williams \& Wilkins.

Lysenko, O. \& Weiser, J. (1974). Bacteria associated with the nematode Neoaplectana carpocapsae and the pathogenicity of this complex for Galleria mellonella larvae. J Invertebr Pathol 24, 332-336.

Moller, L. V. M., Arends, J. P., Harmsen, H. J. M., Talens, A., Terpstra, P. \& Slooff, M. J. H. (1999). Ochrobactrum intermedium infection after liver transplantation. J Clin Microbiol 37, 241-244.

Poinar, G. O., Jr \& Thomas, G. M. (1966). Significance of Achromobacter nematophilus Poinar and Thomas (Achromobacteriaceae: Eubacteriales) in the development of the nematode DD-136 (Neoaplectana sp., Steinernematidae). Parasitology 56, 385-390.

Poinar, G. O., Jr, Thomas, G. M., Presser, S. B. \& Hardy, J. L. (1982). Inoculation of entomogenous nematodes, Neoaplectana and Heterorhabditis and their associated bacteria, Xenorhabdus spp. into chicks and mice. Environ Entomol 11, 137-138.

Romero, C., Gamazo, C., Pardo, M. \& Lopez-Goni, I. (1995). Specific detection of Brucella DNA by PCR. J Clin Microbiol 33, 615-617.

Ryu, E. (1937). A simple method of staining bacterial flagella. Kitasato Arch Exp Med 14, 218-219.

Saitou, N. \& Nei, M. (1987). The neighbor-joining method: a new method for reconstructing phylogenetic trees. Mol Biol Evol 4, 406-425.

Schafer, A., Konrad, R., Kuhnigk, T., Kampfer, P., Hertel, H. \& Konig, H. (1996). Hemicellulose-degrading bacteria and yeasts from the termite gut. J Appl Bacteriol 80, 471-478.

Thomas, G. M. \& Poinar, G. O., Jr (1979). Xenorhabdus gen. nov., a genus of entomopathogenic nematophilic bacteria of the family Enterobacteriaceae. Int J Syst Bacteriol 29, 352-360.

Thompson, J. D., Gibson, T. J., Plewniak, F., Jeanmougin, F. \& Higgins, D. G. (1997). The CLUSTAL-X Windows interface: flexible strategies for multiple sequence alignment aided by quality analysis tools. Nucleic Acids Res 25, 4876-4882.

Velasco, J., Romero, C., Lopez-Goni, I., Leiva, J., Diaz, R. \& Moriyon, I. (1998). Evaluation of the relatedness of Brucella spp. and Ochrobactrum anthropi and description of Ochrobactrum intermedium sp. nov., a new species with a closer relationship to Brucella spp. Int J Syst Bacteriol 48, 759-768.

Wiesburg, G. W., Barns, S. M., Pelletier, D. A. \& Lane, D. J. (1991). $16 \mathrm{~S}$ ribosomal DNA amplification for phylogenetic study. $J$ Bacteriol 173, 697-703.

Wouts, W. M. (1990). The primary form of Xenorhabdus species (Enterobacteriaceae, Eubacteriales) may consist of more than one bacterial species. Nematologica 36, 313-318.

Yanagi, M. \& Yamasato, K. (1993). Phylogenetic analysis of the family Rhizobiaceae and related bacteria by sequencing of $16 \mathrm{~S}$ rRNA gene using PCR and DNA sequencer. FEMS Microbiol Lett 107, 115-120.

Yu, W. L., Lin, C. W. \& Wang, D. Y. (1998). Clinical and microbiological characteristics of Ochrobactrum anthropi bacteremia. J Formos Med Assoc 97, 106-112.

Received 14 June 1999; revised 11 October 1999; accepted 16 November 1999. 